\title{
Impact of Biosensor Permittivity on a Double-Gate nTFET Ambipolar Current
}

\author{
C. N. Macambira ${ }^{1}$, P. G. D. Agopian ${ }^{1,2}$, J. A. Martino ${ }^{1}$ \\ ${ }^{1}$ LSI/PSI/USP, University of Sao Paulo, Sao Paulo, Brazil \\ ${ }^{2}$ Sao Paulo State University (UNESP), Sao Joao da Boa Vista, Brazil \\ correspondent author email: christianmacam@usp.br
}

The goal of this work is to analyze the effect of gate to drain underlapping on n-type Tunnel-FET (nTFET) devices, filled with different dielectric permittivity material $(\mathrm{k})$ in order to simulate the bio element materials. The results show that the use of Tunnel-FET ambipolar current presents high sensitivity for using it as biosensor devices for transistors with the drain underlap of $15 \mathrm{~nm}$ and total channel length of $50 \mathrm{~nm}$ for the range studied in this paper.

\section{Introduction}

Biosensors are defined as any device that senses and transmits information about a biological element. The importance of biosensors for health and environment monitoring increase in the past decades, due the global warming, pollution and new biological pathogens.

In order to achieve better sensing and to scale down the device dimensions and other advantages (1), the use of field effect transistor (FETs) as biosensors have been studied recently (1-4). One new FET type that has been used recently as biosensor is the tunnel field effect transistor (TFET). The TFET have more benefits than others technologies such as metal oxide semiconductor FETs (MOSFET) (5). However, TFETs have a parasitic effect that is an ambipolar current for negative polarization of the gate in the case of nTFET (6). In TFET biosensor, this effect can be used to sense different biological particle in contact with the device, as reported in (7).

The sensing is possible due the fact that biologicals particles have different permittivity from each other (8), thus it is possible to determine a specific particle in function of its permittivity. The ambipolar current is sensitive for changing in the permittivity of biological particle and can be used for biosensor purpose.

\section{Device Characteristics}

The gate length $\left(\mathrm{L}_{\mathrm{G}}\right.$, where $\left.\mathrm{L}_{\mathrm{G}}=\mathrm{L}_{\mathrm{SD}}-\mathrm{L}_{\mathrm{U}}\right)$ was studied changing the drain underlap $\left(\mathrm{L}_{\mathrm{U}}\right)$ for a range of $0 \mathrm{~nm}$ (self-aligned) to $15 \mathrm{~nm}$ of drain underlap, with step of $5 \mathrm{~nm}$. The total channel length ( $\mathrm{L}_{\mathrm{SD}}$, where $\mathrm{L}_{\mathrm{SD}}=\mathrm{L}_{\mathrm{G}}+\mathrm{L}_{\mathrm{U}}$ ) was evaluated fixing the $\mathrm{L}_{\mathrm{G}}=50 \mathrm{~nm}$ and adding the drain underlap part. In all cases, different dielectric permittivity (k) was considered in these analyses representing the bio element. The structure of the Double Gate DG-nTFET biosensor is shown in Figure 1. 


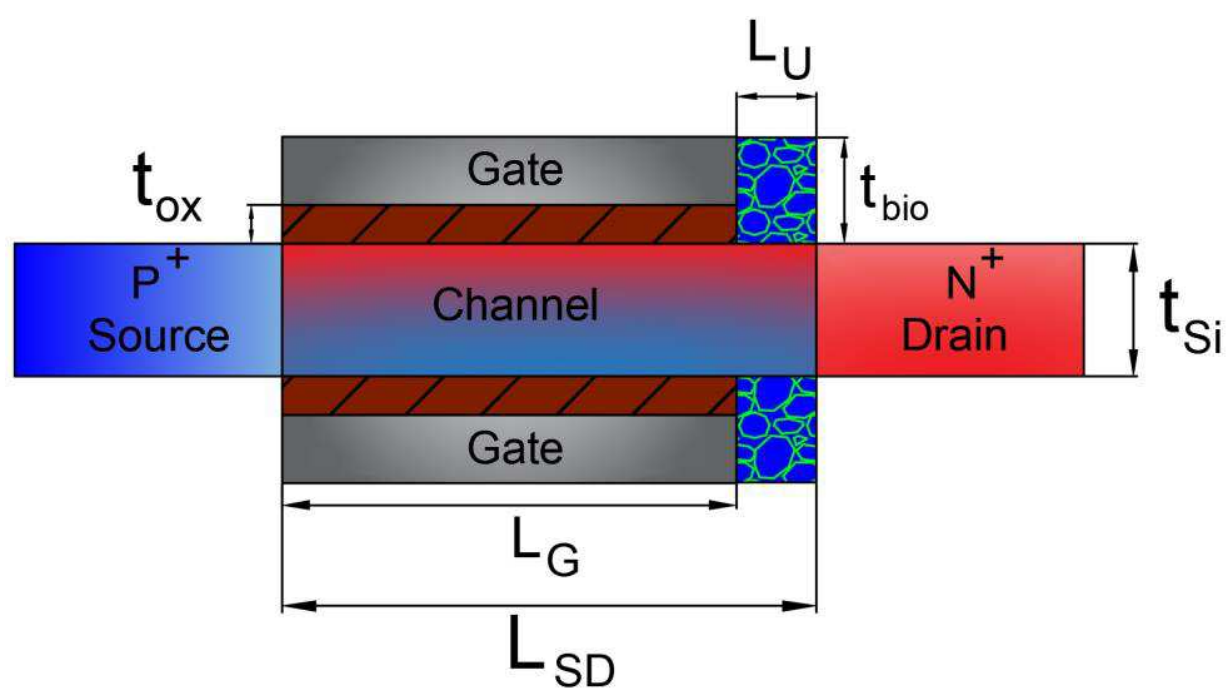

Figure 1. Structure of the DG-nTFET working like a biosensor.

The simulations were performed using Sentaurus simulator from Synopsys and the parameters used for simulation are: silicon film thickness, $t_{\mathrm{Si}}=10 \mathrm{~nm}$, equivalent oxide thickness $\mathrm{EOT}=1 \mathrm{~nm}$, channel length $\mathrm{L}_{\mathrm{SD}}=50 \mathrm{~nm}$, thickness of the bio element $\mathrm{t}_{\mathrm{Bio}}=10$ $\mathrm{nm}$ and the length of the drain and source regions $\mathrm{L}_{\mathrm{D}}=\mathrm{L}_{\mathrm{S}}=100 \mathrm{~nm}$. The gate (Titanium Nitride) work function $=4.7 \mathrm{eV}$, source doping $\mathrm{N}_{\mathrm{A}}=1.10^{20} \mathrm{~cm}^{-3}$, drain doping $\mathrm{N}_{\mathrm{D}}=1.10^{20}$ $\mathrm{cm}^{-3}$ and channel doping $\mathrm{N}_{\mathrm{D}}=1.10^{7} \mathrm{~cm}^{-3}$. The models used are nonlocal band-to-band tunneling (BTBT), Shockley-Read-Hall (SRH) recombination and band-gap narrowing (BGN) model (9).

\section{Analysis and Results}

The transfer characteristic of nTFETs with different underlap values are shown in Fig.2. It is observed that with the increment of $\mathrm{LU}_{U}$ the TFET ambipolar current (drain to channel tunneling) decreases, as already reported in (10).

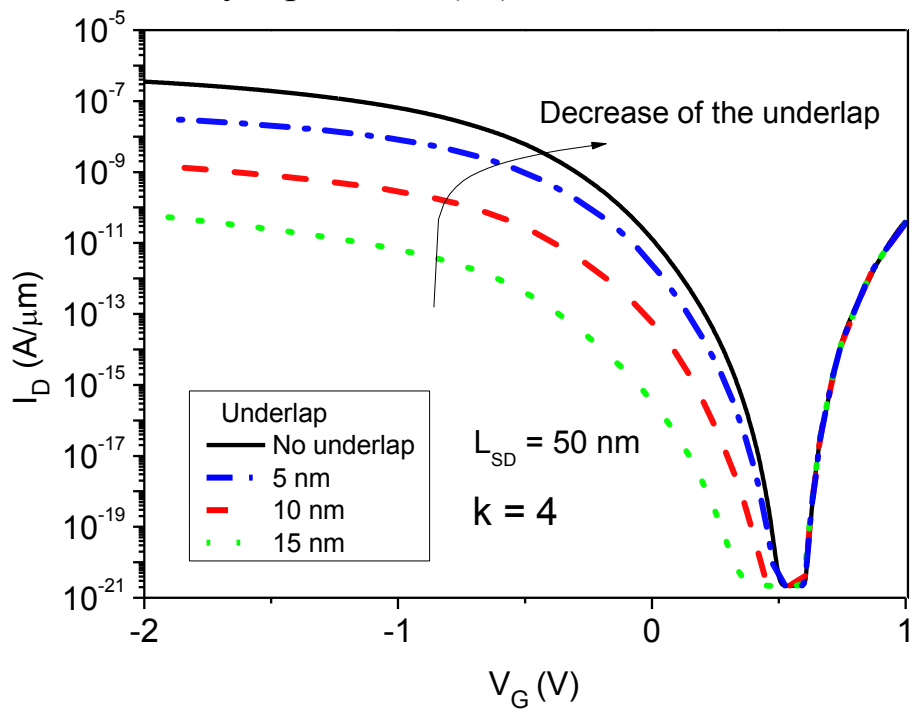

Figure 2. Transfer characteristic of DG-nTFET of $\mathrm{L}_{\mathrm{SD}}=50 \mathrm{~nm}$ and bio element constant dielectric $\mathrm{k}=4$ for different drain underlap lengths. 
However, if the $\mathrm{k}$ values increase and the underlap is constant $\left(\mathrm{L}_{U}=15 \mathrm{~nm}\right)$, the ambipolar currents increase as can be seen in Fig.3.

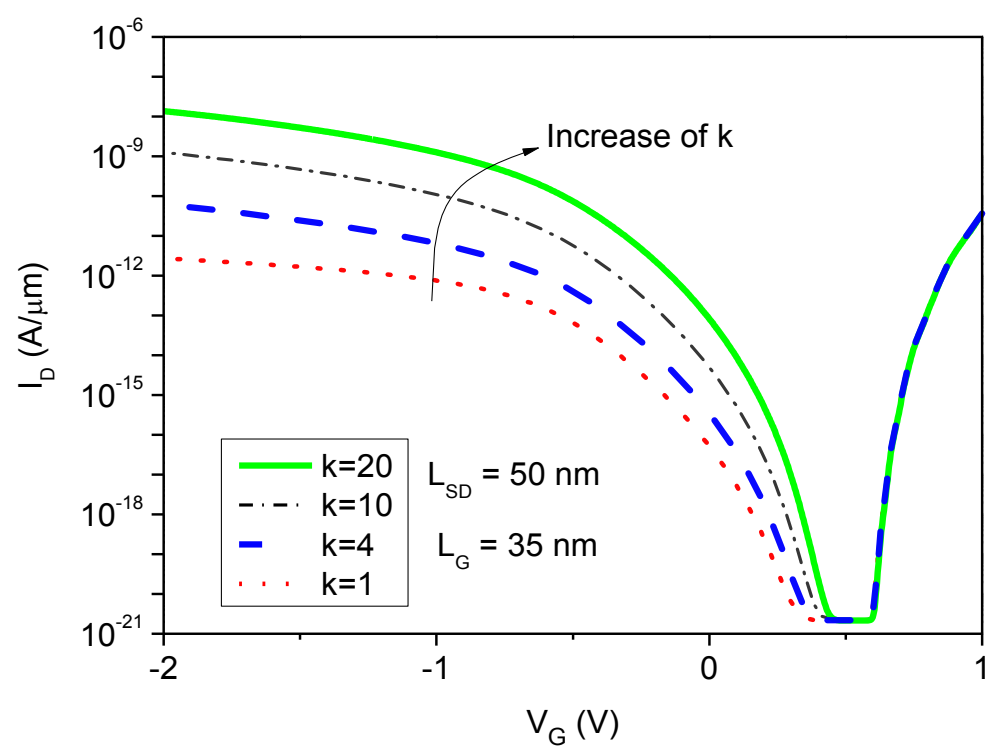

Figure 3. Transfer characteristic of DG-nTFET of $15 \mathrm{~nm}$ drain underlap and LSD constant for different bio elements with different dielectric constant $(\mathrm{k})$.

This effect can be explained from Fig.4, where it is possible to see that the tunneling length becomes thinner when $\mathrm{k}$ raises due to improvement of the tunneling between drain and channel.

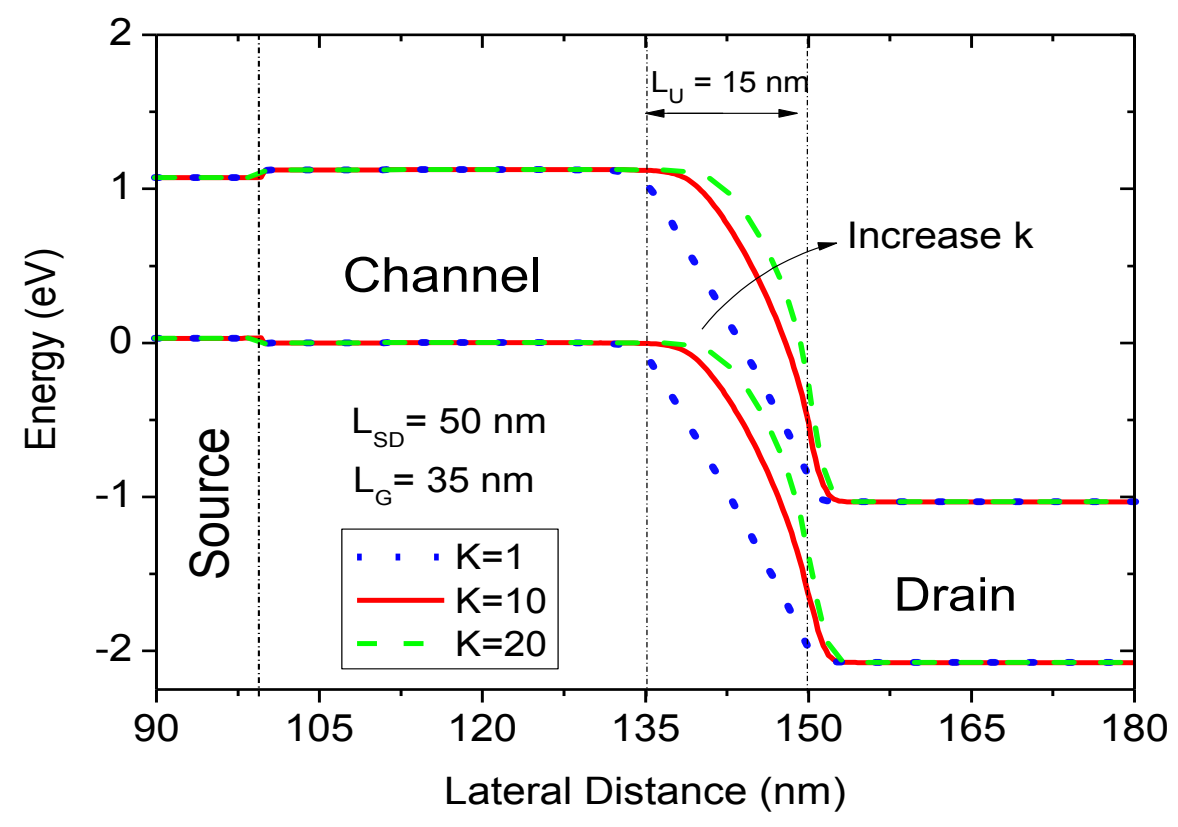

Figure 4. Simulated energy band diagram at $1 \mathrm{~nm}$ below the oxide-silicon interface for $\mathrm{L}_{\mathrm{SD}}$ constant $(50 \mathrm{~nm})$ and an underlap, $\mathrm{L}_{\mathrm{U}}=15 \mathrm{~nm}$ for different k-values, biased at $\mathrm{V}_{\mathrm{G}}=-2$ $\mathrm{V}$ and $\mathrm{V}_{\mathrm{DS}}=1 \mathrm{~V}$. 


\section{$\underline{\text { Sensitivity }}$}

In order to analyze a better configuration for a biosensor device, a sensitivity parameter defined as Sensivity $=I_{D(K=n)} / I_{D(k=1)}$, where $n$ is the value of the corresponding $k$, was used for comparing all different type of configurations studied in this paper. The sensitivity increases with the $\mathrm{k}$ value and with different $\mathrm{Lu}_{\mathrm{U}}$ is shown in Fig.5. The best sensitivity is obtained for high $\mathrm{K}$ and high underlap region.

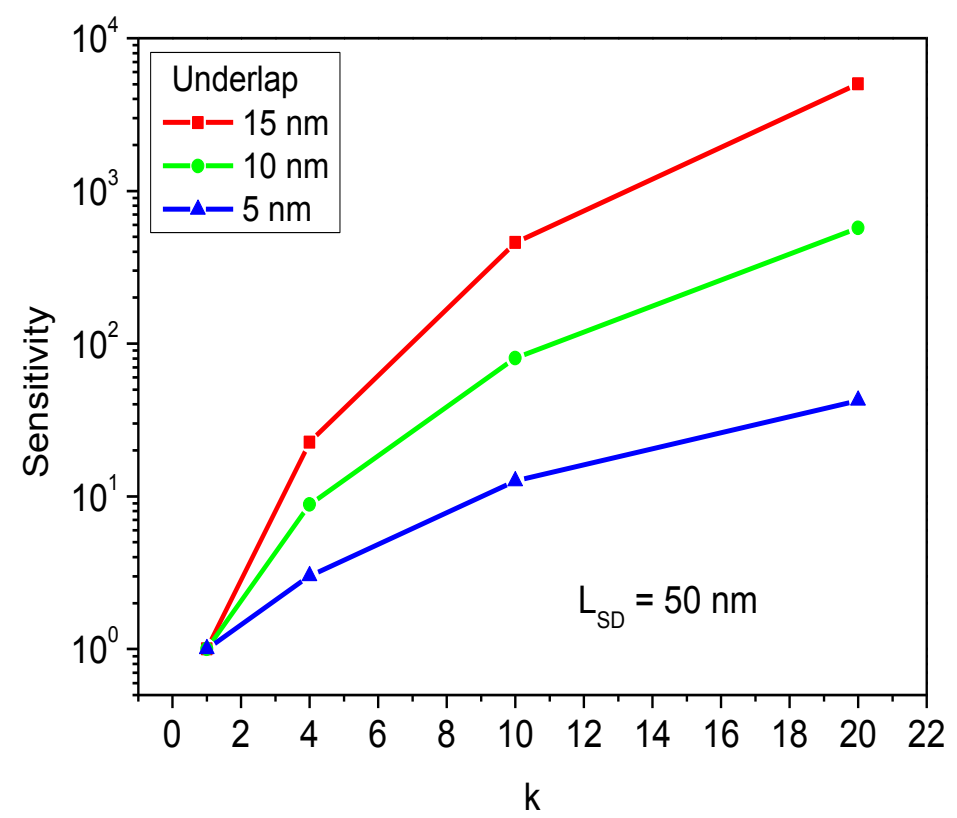

Figure 5. Sensitivity as a function of dielectric constants with $\mathrm{L}_{\mathrm{SD}}=50 \mathrm{~nm}$, for DGnTFET biased at $V_{G}=-2 \mathrm{~V}$ and $\mathrm{V}_{\mathrm{DS}}=1 \mathrm{~V}$ for different drain underlap lengths.

In the case of the device with $\mathrm{L}_{\mathrm{G}}$ fixed at $50 \mathrm{~nm}$, the Fig. 6 shows that the sensitivity increases with $\mathrm{k}$ and the highest sensitivity was obtained for lower underlap $(5 \mathrm{~nm})$.

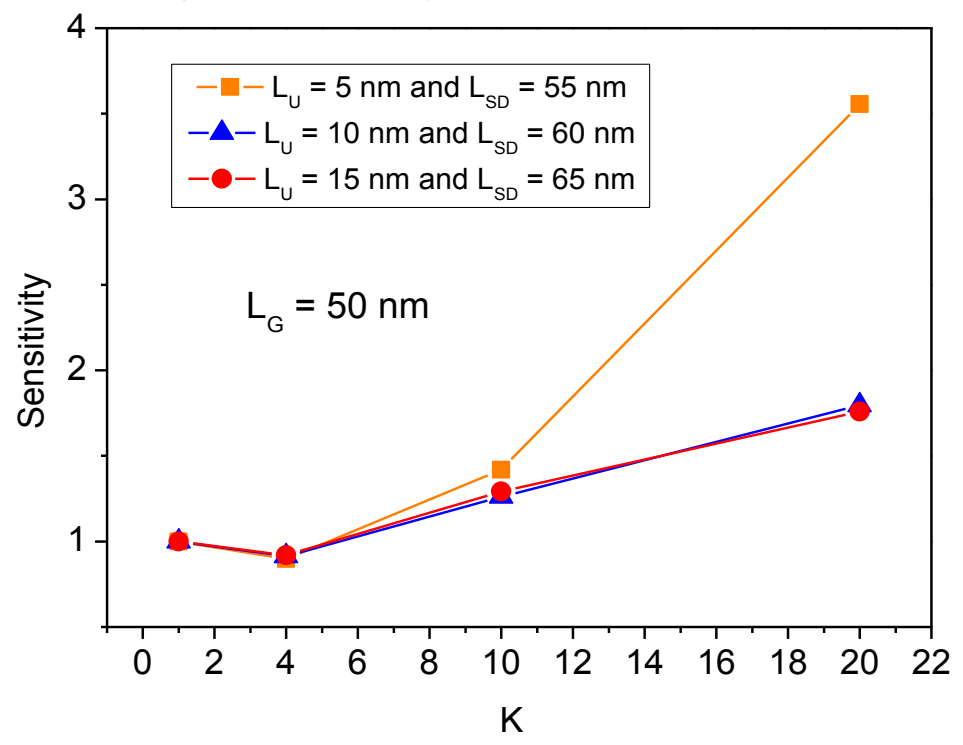

Figure 6. Sensitivity as a function of dielectric permittivity for different $\mathrm{L}_{U}$ and $\mathrm{L}_{\mathrm{SD}}$. 
It can be explained analyzing the band diagram of the Fig.7, where it is possible to notice that the tunnel length decreases for lower underlap region.

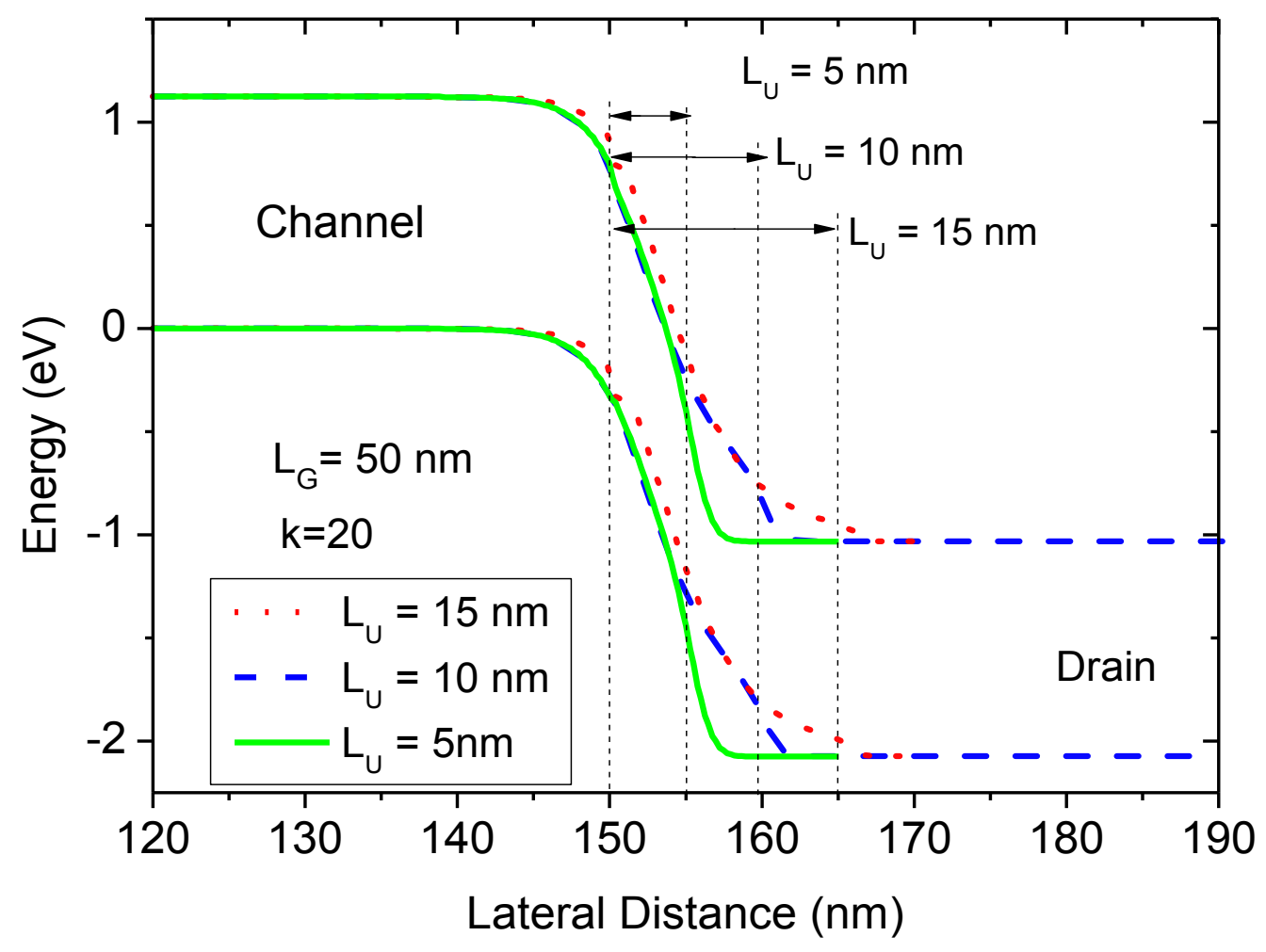

Figure 7. Simulated energy band diagram below $1 \mathrm{~nm}$ from the oxide-silicon interface for $L_{G}$ constant (50nm) and $k=4$ for different $L_{U}$ biased at $V_{G}=-2 V$ and $V_{D S}=1 \mathrm{~V}$.

\section{Conclusions}

An investigation of the impact of biosensor permittivity on a DG-nTFET ambipolar current was done. The bio elements detection using the drain underlap region showed high sensitivity, of orders of magnitude for different drain underlap ( $\mathrm{Lu}_{\mathrm{U}}$ ) and dielectric permittivity material $(\mathrm{k})$ values. The highest sensitivity for an nTFET biosensor was observed for a drain underlap $\mathrm{L}_{U}=15 \mathrm{~nm}$ (higher $\mathrm{L}_{\mathrm{U}}$ ), $\mathrm{L}_{\mathrm{SD}}=50 \mathrm{~nm}$ (smaller $\mathrm{L}_{\mathrm{SD}}$ ) and higher $\mathrm{k}$ bio element for the range studied in this paper.

\section{Acknowledgments}

The authors would like to thank FAPESP, CNPq and CAPES for the financial support.

\section{References}

1. R. Narang, M. Saxena, R. S. Gupta, and M. Gupta, IEEE Electron Device Lett., 33, 266-268 (2012).

2. C. Kataoka-Hamai and Y. Miyahara, IEEE Sens. J., 11, 3153-3160 (2011). 
3. S. Singh, P. N. Kondekar, and N. K. Jaiswal, Microelectron. Eng., 149, 129-134 (2016) http://dx.doi.org/10.1016/j.mee.2015.10.005.

4. J. A. Martino, P. G. D. Agopian, E. Simoen, and C. Claeys, Proc. - 2014 IEEE 12th Int. Conf. Solid-State Integr. Circuit Technol. ICSICT 2014, 3-6 (2014).

5. P. G. D. Agopian, R. Rooyackers, A. Vandooren, E. Simoen, A. Thean and C. Claeys, 2016 Jt. Int. EUROSOI Work. Int. Conf. Ultim. Integr. Silicon, EUROSOI-ULIS 2016, 13-15 (2016).

6. A. Shaker, M. El Sabbagh, and M. M. El-Banna, IEEE Trans. Electron Devices, 64, 3541-3547 (2017).

7. D. B. Abdi and M. J. Kumar, Superlattices Microstruct., 86, 198-202 (2015) http://dx.doi.org/10.1016/j.spmi.2015.07.052.

8. A. Cuervo, P. D. Dans, J. L. Carrascosa, M. Orozco, G. Gomila and L. Fumagalli, Proc. Natl. Acad. Sci., 111, E3624E3630 (2014)

http://www.pnas.org/cgi/doi/10.1073/pnas.1405702111.

9. Synopsys TCAD Sentaurus, (2017). Release: L-2016.03.

10. P. G. D. Agopian, M. D. V. Martino, S. G. S. Filho, J. A. Martino, R. Rooyackers, D. Leonelli and C. Claeys, Solid. State. Electron., 78, 141-146 (2012) http://dx.doi.org/10.1016/j.sse.2012.05.053. 